\title{
Inovação na Biblioteca Universitária: relato de experiência da Udesc
}

\author{
Innovation in the University Library: Udesc's experience report
}

\author{
Letícia Lazzari \\ Mestra em Gestão de Unidades de Informação \\ Universidade do Estado de Santa Catarina \\ leticia.lazzari@udesc.br \\ Luiza da Silva Kleinübing \\ Mestra em Gestão de Unidades de Informação \\ Universidade do Estado de Santa Catarina \\ luiza.kleinubing@udesc.br \\ Marcela Reinhardt de Souza \\ Mestra em Gestão de Unidades de Informação \\ Universidade do Estado de Santa Catarina \\ marcela.souza@udesc.br \\ Orestes Trevisol Neto \\ Mestre em Ciência da Informação \\ Universidade do Estado de Santa Catarina \\ orestes.trevisol@udesc.br
}

\section{Resumo}

Diante do atual cenário, marcado pelos reflexos da pandemia da covid-19 e a virtualização dos serviços, desenvolver projetos inovadores em bibliotecas se torna imprescindível. Esse relato objetiva compartilhar a experiência da Biblioteca Universitária da Universidade do Estado de Santa Catarina (Udesc) na oferta de serviços inovadores por meio da descrição dos projetos desenvolvidos pela sua equipe. Os projetos são apresentados nas seguintes categorias: 1) desenvolvimento de habilidades informacionais; 2) promoção de atividades culturais; 3) promoção da cultura da colaboração; 4) inovação para o empréstimo e 5) serviços voltados à comunicação científica. Considera-se que, para inovar, é preciso investimento em recursos humanos e infraestrutura, apoio dos setores e das instituições, engajamento da equipe e enfoque nas ações em que há percepção de valor por parte da comunidade. Como consequência, a BU Udesc conquistou mais visibilidade, recebeu feedbacks positivos, tornou-se referência diante da comunidade e estabeleceu relação de cooperação no ambiente interno e externo.

\section{Palavras-chave}

Inovação. Serviços de informação. Biblioteca Universitária.

\section{Abstract}

In view of the current scenario, marked by the reflexes of the pandemic and virtualization of services, developing innovative projects in libraries becomes essential. This report aims to share the experience of the Biblioteca Universitária da Udesc in offering innovative services through the description of the projects developed by its team. The projects are presented in the following categories: development of informational skills, promotion of cultural activities, promotion of the culture of collaboration, innovation for the loan and services focused on scientific communication. It is considered that to innovate it is necessary to invest in human resources and infrastructure, support from sectors and institu- 
tions, team engagement and focus on actions where there is perceived value on the part of the community. As a consequence, BU Udesc gained more visibility, received positive feedbacks, became a reference before the community and established a cooperative relationship in the internal and external environment.

\section{Keywords}

Innovation. Information services. University Library.

\section{INTRODUÇÃO}

Quem não é visto não é lembrado. Partindo dessa conhecida frase e da reflexão que traz consigo, destacamos o quão fundamental é enaltecer a contribuição da biblioteca para sua comunidade. Oferecer serviços que agreguem valor e espaços acolhedores para os seus usuários é imprescindível, de modo que eles se tornem defensores deste espaço e promotores da biblioteca como um serviço essencial à sociedade.

A sustentabilidade de qualquer organização e também das bibliotecas está diretamente associada ao valor percebido pela sua comunidade quanto aos seus serviços e espaços. A inovação vai ao encontro deste objetivo, como afirmam Zaninelli, Nogueira e Peres $(2019$, p. 3) que afirmam que nas instituições públicas, "a necessidade de inovar se baseia no anseio que as organizações possuem de se [...] manterem sustentáveis" e assim se perpetuarem.

Neste documento, relatamos a experiência da Biblioteca Universitária (BU) da Universidade do Estado de Santa Catarina (Udesc), que é uma instituição pública estadual, atuante nas áreas de ensino, pesquisa e extensão, dispondo de uma estrutura multicampi, com 12 unidades distribuídas em nove cidades do Estado de Santa Catarina, além de 32 polos de apoio presencial para o ensino à distância, em parceria com a Universidade Aberta do Brasil do Ministério da Educação (UAB/MEC). Atualmente, são aproximadamente 15 mil alunos distribuídos em 59 cursos de graduação e 48 cursos de pós-graduação, oferecidos gratuitamente (UNIVERSIDADE DO ESTADO DE SANTA CATARINA, [202?]).

A BU Udesc é um órgão suplementar com a finalidade de oferecer serviços de informação, por meio de um sistema descentralizado de bibliotecas setoriais que se complementam (UNIVERSIDADE DO ESTADO DE SANTA CATARINA, 2019, p. 1). São 11 bibliotecas distribuídas por todo o Estado de Santa Catarina junto aos Centros de Ensino que atendem alunos, professores, pesquisadores e técnicos universitários. Além disso, as Bibliotecas da Udesc estão abertas à comunidade externa, que pode usufruir de seus espaços e acervo localmente.

Alguns dos serviços ofertados pela BU Udesc são: empréstimo entre instituições, levantamento bibliográfico, visitas orientadas, capacitações, disponibilização de tutoriais, catalogação na fonte, registros de Digital Object Identifier (DOI) para artigos de periódicos Udesc e livros da Editora Udesc, atendimento especializado aos periódicos Udesc, atividades artísticas e culturais, empréstimo de objetos, entre outros.

Com o objetivo de permanecer essencial à comunidade, oferecer melhores experiências na utilização de seus serviços e disponibilizar espaços acolhedores, a BU Udesc passou por uma transformação a partir de 2019. Foram reestruturados os seus objetivos, sua imagem, essência e a sua relação com a comunidade. Juntas, as onze bibliotecas setoriais, coordenadas pela Biblioteca Universitária, aderiram ao desafio de inovar ao invés de apenas sobreviver (LANKES, 2016). 
Objetiva-se, neste trabalho, relatar a experiência da BU Udesc na oferta de serviços inovadores. Por meio desse relato, buscamos inspirar outros profissionais em suas respectivas bibliotecas a oferecerem novos serviços ou adaptarem aqueles já existentes, bem como estimular a reflexão e diálogo sobre essas práticas nos serviços das bibliotecas. Além disso, é sempre importante disseminar práticas que estreitam as relações com a comunidade acadêmica e externa.

Justifica-se, por meio deste relato, a necessidade de compartilhar experiências exitosas com outros bibliotecários e futuros profissionais, a fim de que vislumbrem possíveis cenários de mudanças em seus locais de trabalho. Além disso, ao escrever o relato de experiência, é possível materializar o trabalho desenvolvido e preservar a memória.

\section{INOVAÇÃO EM BIBLIOTECAS UNIVERSITÁRIAS}

Segundo Cunha e Cavalcanti (2008, p. 53), a biblioteca universitária caracteriza-se por ser um órgão mantido "por uma instituição de ensino superior e que atende às necessidades de informação dos corpos docente, discente e administrativo, tanto para apoiar as atividades de ensino, quanto de pesquisa e extensão".

$\mathrm{Na}$ literatura encontramos diversos termos que definem essa comunidade cuja biblioteca universitária atende, dentre os quais estão: usuário, leitor, consulente, interagente e cliente. Independente do termo utilizado, eles representam tanto a comunidade universitária quanto a própria comunidade externa que faz uso dos serviços ofertados pela unidade de informação (CORRÊA, 2014).

Rossi e Vianna $(2018$, p. 7) destacam que, ao contrário do que afirmava o senso comum "a biblioteca não deixou e não deixará de existir com o advento das tecnologias, embora precise se reinventar constantemente para atender as necessidades e expectativas dos usuários".

Nesse sentido, a continuidade e perpetuação das organizações, inclusive das bibliotecas, está diretamente relacionada à sua capacidade de ofertar serviços e produtos alinhados à necessidade de seus clientes. Conforme já mencionado, a instituição só será sustentável se existirem pessoas interessadas em usufruir o que é fornecido. A efemeridade dessas demandas, necessidades e interesses dos clientes propulsionam as organizações a olharem atentamente para o mercado, monitorando e buscando anteceder as mudanças, reajustando a rota para se adaptar aos novos cenários (ZANINELLI; NOGUEIRA; PERES, 2019).

Nesse contexto, a atitude inovadora se apresenta como ferramenta fundamental, pois a inovação busca a alteração dos produtos e serviços ofertados, bem como modificar as circunstâncias e forma como são criados e entregues ao mercado, tendo em vista as necessidades e interesses do seu público-alvo (BESSANT; TIDD, 2019).

Conforme consta no Manual de Oslo, elaborado pela Organização para a Cooperação e Desenvolvimento Econômico (OCDE), considerado importante instrumento sobre os conceitos e diretrizes de inovação, "o requisito mínimo para se definir uma inovação é que o produto, o processo, o método de marketing ou organizacional sejam novos (ou significativamente melhorados) para a empresa" (ORGANIZAÇÃO PARA COOPERAÇÃO E DESENVOLVIMENTO ECONÔMICO, 2006, p. 56).

Assim, a inovação não se limita necessariamente pela exigência de ser algo totalmente novo para uma biblioteca, mas sim, novidade ou melhoria dentro da própria instituição, sejam elas implementadas nos processos internos ou nos serviços ofertados aos usuários. 
Nessa perspectiva, apresentamos os dois patamares de inovação encontrados na literatura da área. O primeiro, a inovação incremental, reflete em mudanças com um impacto no âmbito local e interno, ocasionado pela reformulação ou transformação de processos já existentes na organização. O segundo patamar da inovação é denominado de radical, representando a criação de algo até então inexistente; são aquelas mudanças que trazem uma novidade para o mundo (BESSANT; TIDD, 2019). Dessa maneira, independentemente do índice de inovação almejado, fica explícito entre os autores da área a importância de se observar as necessidades dos clientes para fomentar este processo, afinal "a importância da inovação depende da perspectiva de quem a usa" (ARAÚJO; SILVA; RADOS, 2017, p. 102).

No âmbito das bibliotecas, Zaninelli, Nogueira e Peres $(2019$, p. 3) corroboram a necessidade de que essas instituições busquem "conhecer o perfil do seu público e oferecer produtos e serviços de informação que vão ao encontro de suas necessidades".

Portanto, a aproximação com a comunidade acadêmica, alunos, professores, servidores e também a comunidade externa, é fundamental para conhecer suas realidades, dificuldades e principalmente suas necessidades, fomentando a inovação nesses espaços e nos serviços necessários diante da realidade que se apresenta.

É pertinente enfatizar a importância das redes de colaboração, afinal, como afirma Lankes (2016, p. 58), as "bibliotecas ruins somente criam acervos. Boas bibliotecas criam serviços [...]. Grandes bibliotecas constroem comunidades". Há necessidade de chamar a comunidade para estar junto e tornar possível a criação de uma linha direta e aberta entre a comunidade e a biblioteca. Quando temos uma comunidade, seus membros deixam de ser "usuários" e passam a ser parceiros, propondo e desenvolvendo projetos e ações.

Correa (2014) corrobora este raciocínio, quando afirma que o termo "usuário" talvez esteja muito obsoleto para definir o público da biblioteca, devido à extrema unilateralidade. A autora propõe o uso do termo interagente, com o objetivo de ressaltar essa relação cada vez mais dinâmica e colaborativa que deve existir entre a biblioteca e sua comunidade.

As bibliotecas têm desafios constantes e para Cunha (2010, p. 1):

Enquanto algumas pessoas estão pessimistas sobre o futuro das bibliotecas, muitos na comunidade vislumbram futuros serviços e produtos de bibliotecas que incorporam novas filosofias, tecnologias e espaços para atender as necessidades de todos os utilizadores de forma mais eficaz, rápida e barata.

Mesmo passados mais de dez anos desta citação, sua relevância permanece, pois, durante a pandemia da covid-19 e de acelerado processo de virtualização, podemos vislumbrar novos cenários e papéis às bibliotecas que encaram os desafios da sociedade contemporânea.

Reforçamos a importância de estarmos atentos às tendências do mercado e às necessidades proeminentes da sociedade e de suas comunidades, em busca da sustentabilidade e continuidade das bibliotecas por meio da inovação de seus serviços e espaços.

\section{INOVAÇÃO NOS SERVIÇOS DE INFORMAÇÃO DA BU UDESC}

Em 2019, ocorreu o lançamento da nova identidade visual da BU Udesc com o objetivo de aproximação da comunidade acadêmica e de apresentar a Biblioteca como um espaço convidativo ao exercício da descontração e criatividade. Esse trabalho contou com o apoio do Departamento de Design do Centro de Artes (Ceart) da instituição. 
A nova identidade tem uma proposta inovadora e trouxe benefícios tanto para a BU Udesc como para seus usuários. Por meio dela, foi possível comunicar a mudança de postura, conceito e imagem dos espaços e serviços das bibliotecas. Gostaríamos que nossos usuários vissem as Bibliotecas da Udesc como um ambiente acolhedor e descontraído, onde as pessoas se encontram para compartilhar livros e pensamentos. Essa mudança contribuiu também para unir as bibliotecas da Udesc, mesmo com as realidades distintas entre elas, a participação e engajamento da equipe em todo o processo se tornaram importantes na oferta de serviços de qualidade.

Para a criação da identidade visual foram pensados elementos visuais que remetessem aos livros, ao pensamento e à troca de informações entre as pessoas. Foram adotados como mascotes da Biblioteca os próprios usuários (em sua diversidade), escritores, inventores, educadores e intelectuais que representem as publicações do acervo da biblioteca, apresentados de uma forma descontraída.

Figura 1 - Material produzido para o lançamento da nova identidade visual da BU UDESC

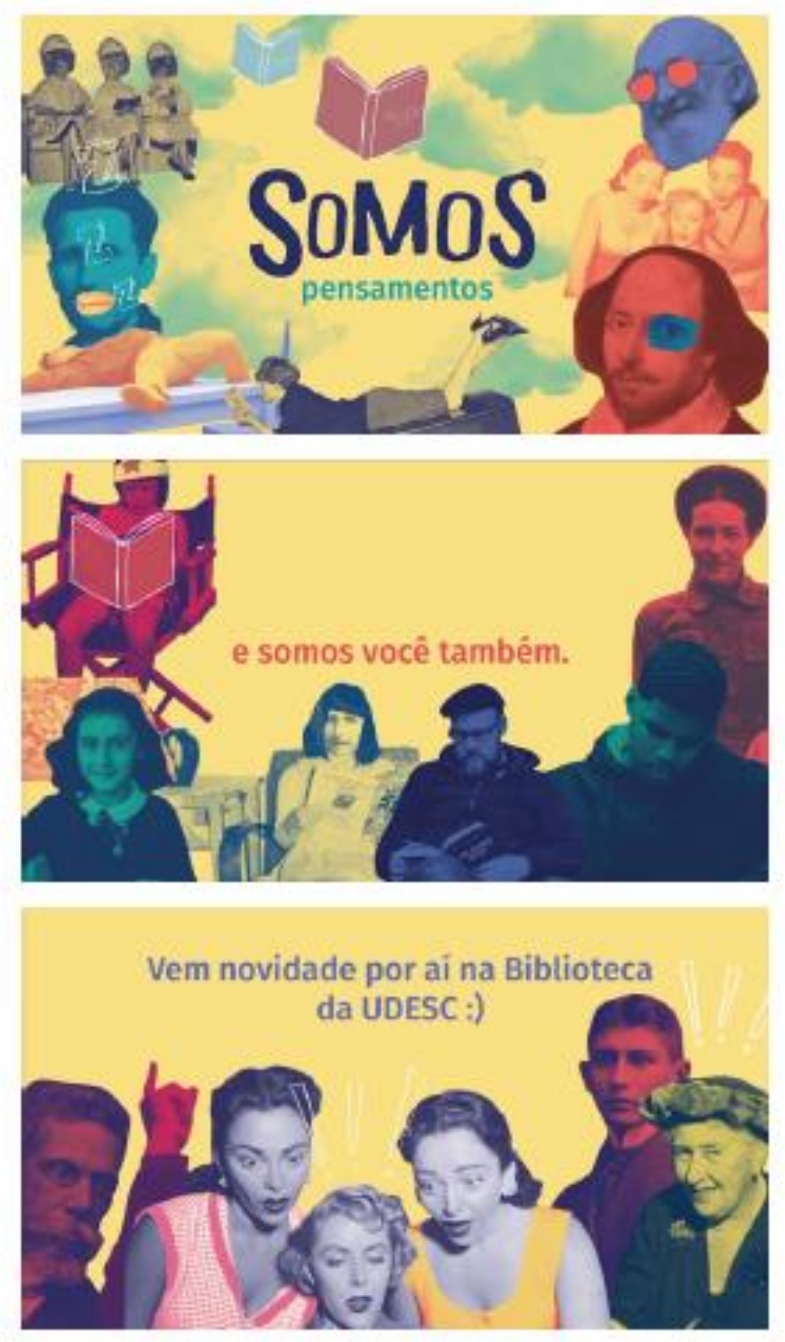

Fonte: Elaborada pelos autores (2021)

Alinhados com a identidade visual, foram desenvolvidos projetos inovadores categorizados conforme seus objetivos e apresentados na figura 2. 
Figura 2 - Inovações desenvolvidas pela BU Udesc a partir de 2019

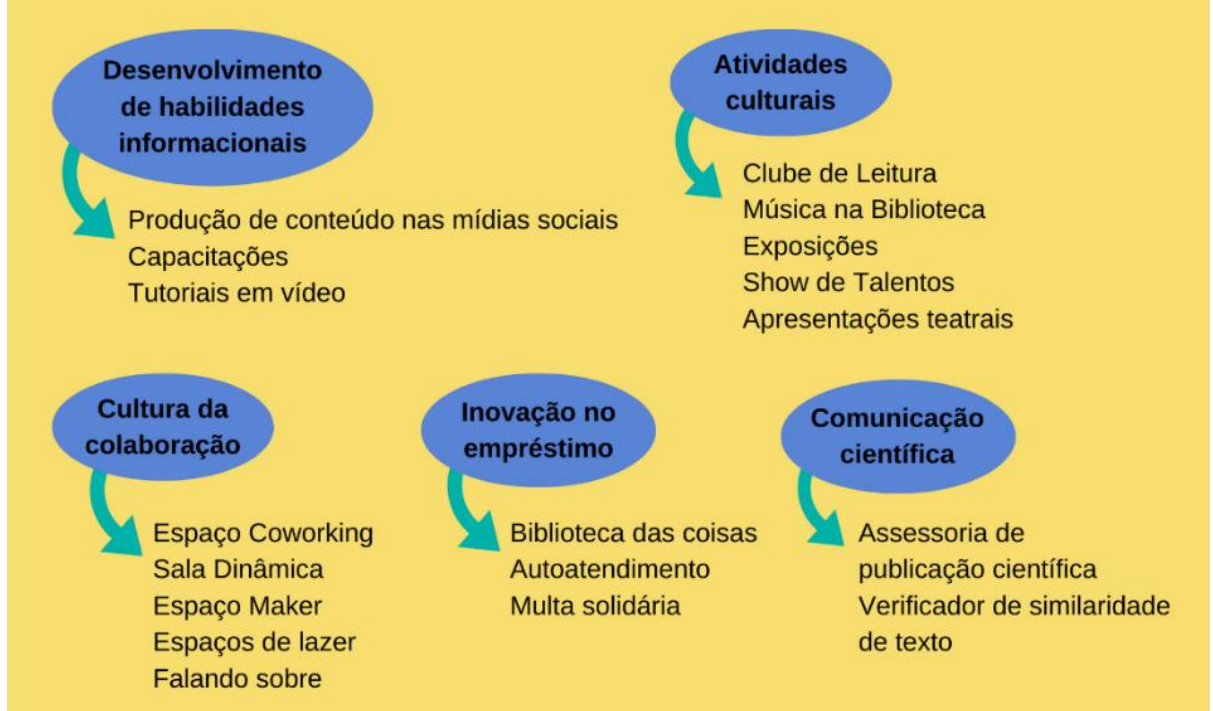

Fonte: Elaborada pelos autores (2021)

Nesta seção, serão apresentados os serviços realizados pela BU Udesc a partir de 2019, divididos entre 1) serviços com foco no desenvolvimento de habilidades informacionais 2) promoção de atividades culturais 3) promoção da cultura da colaboração 4) inovações para os empréstimos 5) serviços voltados à comunicação científica.

\subsection{Serviços com foco no desenvolvimento de habilidades informacionais}

Em 2019, as bibliotecas da Udesc empreenderam esforços para a criação dos conteúdos divulgados nas suas mídias sociais (Facebook, Instagram e YouTube), aplicando o conceito da sua identidade visual. Em 2020, em decorrência da pandemia, foi criado um Grupo de Trabalho (GT) de Mídias Sociais para analisar o uso destas ferramentas pelas bibliotecas. Como resultado dos estudos feitos pelo grupo, optou-se pela unificação dos perfis das bibliotecas no Facebook e Instagram e pelo aprimoramento do canal do YouTube.

Além disso, o GT criou um planejamento mensal de publicações, no qual é possível acompanhar todo o processo de concepção das ideias para os conteúdos a serem publicados e demandas até a sua publicação. Destaca-se que, desde 2019, a BU Udesc conta com a parceria de alunos e docentes do Curso de Design da Universidade, os quais produzem as artes e editam os vídeos, enquanto o GT pensa nas ações, identifica as demandas e propõe o conteúdo.

Com a unificação dos perfis no Facebook e Instagram, percebemos aumento significativo de seguidores e interação, intensificando nossa comunicação com a comunidade. No YouTube obtivemos um crescimento exponencial. Em março de 2020 havia aproximadamente 100 inscritos e um ano depois, passamos de 2300 inscritos. No Instagram, além da divulgação de conteúdo por meio de artes e fotos, passamos a fazer lives que compõem o projeto "Falando Sobre", do qual falaremos na seção 3.3 deste trabalho. Em resumo, a produção de conteúdo envolve artes, fotos, vídeos que traduzem os serviços e ações da BU Udesc.

Diante do cenário de virtualização, percebemos a necessidade de criar um calendário de capacitações que fosse ao encontro das demandas da comunidade acadêmica, auxiliando o público interno e externo nas atividades de busca, seleção e uso da informação nas bases de dados, aplicação de normas da Associação Brasileira de Normas Técnicas (ABNT), domí- 
nios das regras de citações, uso dos gerenciadores bibliográficos (Mendeley, EndNote e Zotero), habilidades sobre uso do Open Researcher and Contributor ID (Orcid), utilização da rede social acadêmica ResearchGate e preenchimento de currículo na Plataforma Lattes. Instigamos o conhecimento acerca da elaboração de pré-projetos de pesquisa, plágio acadêmico, publicação de artigos científicos, revisão sistemática, ciência aberta e apresentações no Microsoft Power Point.

Tais temáticas foram ministradas por bibliotecárias e bibliotecários da Udesc e convidados externos. Utilizamos o serviço Conferência Web, da Rede Nacional de Ensino e Pesquisa (RNP)1, para as transmissões ao vivo no canal do Youtube, com emissão de certificados aos participantes. As gravações estão disponíveis no canal e favoreceram diretamente o crescimento e visibilidade do canal. Este projeto foi intitulado BU Capacita e finalizou 2020 com 28 capacitações. Diante do sucesso e feedback continuamos o BU Capacita em 2021.

No ano de 2019, os bibliotecários com apoio da equipe de design, elaboraram vídeos tutoriais dos serviços disponibilizados pela biblioteca. Em 2020, a produção desses tutoriais foi intensificada, entendendo sua importância para uma comunicação virtual e dinâmica. Nossos tutoriais são breves, com duração média de 4 minutos, e instruem sobre o acesso aos acervos eletrônicos (e-books, o Portal de Periódicos Capes, normas da ABNT), funcionalidades do catálogo on-line (Pergamum), utilização do Sistema de Geração da Ficha Catalográfica (dissertações e teses) e uso do software Microsoft Teams.

Nessa perspectiva, criamos tutoriais para a campanha BU Facilita, com o objetivo de auxiliar os alunos, de forma rápida, na formatação de trabalhos acadêmicos, complementando as instruções que constam no Manual de Trabalhos Acadêmicos da Udesc. Ressalta-se que os tutorais são utilizados pelo setor de referência da BU Udesc nas respostas pontuais e na disseminação dos conteúdos. Assim, pretendemos continuar produzindo estes materiais, em vídeos e outros formatos de vídeos, diante das demandas identificadas pela equipe e por meio de feedbacks da comunidade.

\subsection{Promoção de atividades culturais}

Pensar a Biblioteca Universitária como um espaço de promoção cultural foi uma das propostas surgidas nesta nova fase da BU Udesc. Diante disso, em 2019 foram criados projetos que nos levaram para além dos muros da biblioteca e trouxeram outras experiências para este espaço que, por muitos anos, teve como foco apenas o suporte ao ensino e à pesquisa. Dentre os projetos, destacam-se o Clube de Leitura, Música na Biblioteca, Exposições, Apresentações Teatrais e o Show de Talentos.

O Clube de Leitura Sem Censura foi criado em 2019, buscando instigar o gosto pela leitura, a reflexão e a crítica. Mensalmente, a comunidade interna e externa é convidada a participar da leitura coletiva de um livro e, posteriormente, encontrar-se para um debate sobre os temas presentes na obra. Em 2020, o clube passou para o formato virtual, ampliando o seu alcance. Desde a sua criação, realizamos oito encontros, lemos oito livros e alcançamos aproximadamente 150 leitores.

Pensando em oferecer um momento de pausa e descontração para a nossa comunidade acadêmica, foi criado o projeto Música na Biblioteca. No início de cada semestre, junto com a programação da recepção dos calouros, foram realizadas apresentações musicais em frente ao prédio da Biblioteca Central. Os artistas convidados são alunos do curso de Música da Udesc. Desde o início do projeto, em 2019, foram realizadas três apresentações musicais.

\footnotetext{
${ }^{1}$ Serviço disponível no link: https://conferenciaweb.rnp.br/
} 
Mensalmente, a Biblioteca Central da Udesc recebeu em seu hall de entrada exposições criadas por alunos do Centro de Artes da Udesc e por membros da comunidade externa. Uma ação que visa dar espaço e visibilidade aos artistas locais, bem como aproximar os usuários da biblioteca destas formas de expressões artísticas. No ano 2019 , foram realizadas seis exposições de arte e, para as novas temporadas, serão criados editais para a seleção dos artistas que tenham interesse em expor seus trabalhos.

Outro projeto desenvolvido foi a realização de apresentações teatrais. Semestralmente, os alunos do curso de Artes Cênicas da Udesc elaboram peças teatrais como prérequisito à conclusão de disciplinas. A biblioteca abriu suas portas para ser palco dessas peças, oferecendo aos alunos um espaço de prática e aos usuários da biblioteca uma nova experiência cultural.

Percebendo o potencial artístico de nossos alunos e entendendo a biblioteca como um espaço convergente de todos os grupos da comunidade acadêmica, durante a programação da Semana do Livro e da Biblioteca de 2019, realizamos o primeiro Show de Talentos, que contou com apresentações musicais, troca-troca de livros, exposições de arte, sorteios e food trucks. Tudo pensado para integrar os alunos, servidores e a comunidade local.

Todos os projetos citados são realizados em parceria com a comunidade acadêmica ou com a comunidade local. Trazendo essas pessoas como parceiras de nossos projetos, aproximamos novos grupos de interesse à biblioteca, tornando nosso público cada vez mais plural e consciente das possibilidades e potencialidades deste espaço.

Alguns destes projetos precisaram ser suspensos, temporariamente, durante a pandemia da covid-19, pois demandam contato direto com o público, mas tão logo a situação seja normalizada, terão seus cronogramas retomados.

\subsection{Promoção da cultura da colaboração}

No ano de 2019, a BU Udesc foi contemplada no Edital da Pró-Reitoria de Ensino para a criação de Espaços Inovadores de Ensino (Espine). Nas bibliotecas, o Espine busca criar espaços mais criativos, convidativos, versáteis, tecnológicos e agregadores. Assim, aproxima as pessoas, promove a interdisciplinaridade e faz da biblioteca um espaço convidativo ao exercício da descontração e criatividade. Integrar a cultura maker, por meio do desenvolvimento, gestão e oferta in loco de oficinas de criatividade, espaços de estar e de troca que suportam e potencializam os processos de ensino-aprendizagem. Trata-se de investir no potencial de produzir e convergir saberes mais que no potencial de silêncio que tem a biblioteca.

Na Biblioteca Central, o Espine foi inaugurado em março de 2020 e conta com três ambientes, o Espaço Coworking, a Sala Dinâmica e o Espaço Maker. O Espaço Coworking foi pensado como local de trabalho compartilhado, em grupo ou individualmente, contendo materiais como mesas rebatíveis, puffs e tela multiuso. A Sala Dinâmica é própria para sediar capacitações, aulas, eventos, rodas de conversa, tendo datashow, arquibancadas, puffs e cadeiras empilháveis, para permitir maior versatilidade de uso do espaço. Já, o Espaço Maker pode ser utilizado à experimentação e à prototipagem de ideias, sendo equipado com impressora 3D, ferramentas, bancada de trabalho, guilhotina de papel e materiais de escritórios.

É importante destacar que, transformar a Biblioteca Central neste espaço inovador de ensino otimizou os recursos investidos, tendo em vista o compartilhamento dos mesmos por todos os cursos ofertados em Florianópolis. Além disso, ela se torna um espaço agrega- 
dor e integrador, pois é o ponto em comum entre todos os cursos, alunos, professores e técnicos.

Além da Biblioteca Central, todas as bibliotecas setoriais da Udesc também receberam um conjunto de itens, formado por tapete de grama sintética, puffs, almofadas e jogos para a criação dos seus próprios espaços de lazer, agregando descontraindo e impactando a percepção e uso do ambiente geral.

Ainda, com o intuito de promover espaços de diálogo entre a comunidade sobre os mais diversos assuntos, foi criado o projeto Falando Sobre. Por meio de rodas de conversa fomenta um espaço democrático para trocas e aprendizados que tem como objetivo o compartilhamento de experiências, informação e conhecimento.

Com a pandemia da covid-19, declarada a partir de março de 2020, as atividades planejadas presencialmente migraram para o ambiente virtual. Assim, promovemos lives, utilizando o perfil da BU no Instagram ${ }^{2}$ à continuidade do Falando Sobre.

Antes da pandemia aconteceu uma roda de conversa e durante o período remoto foram produzidas oito lives no Instagram. Abordaram-se temas como o racismo estrutural, questões de gênero, voluntariado, organização pessoal, autoconhecimento, ensino remoto, leitura e literatura. Para esse projeto, contamos com a colaboração de 20 convidados.

\subsection{Inovações para o empréstimo}

Conforme já mencionado, a inovação não precisa necessariamente ser no grau radical. Mudar a forma de ofertar um serviço já existente, também, pode representar uma inovação à comunidade.

O empréstimo de livros é um serviço essencial em qualquer biblioteca e o acesso à informação pode ser um dos motivos para as pessoas buscarem este espaço. De todo modo, pode-se pensar em formas de inová-lo e o modernizar com base nas necessidades da comunidade e na incorporação de novas ferramentas tecnológicas.

A Biblioteca Universitária da Udesc realizou a aquisição de equipamentos de autoatendimento para todas as suas unidades, o que possibilitou o autoempréstimo e autodevolução de livros. Esta tecnologia tornou mais ágeis estes processos e permitiu aos servidores que antes atuavam apenas neste atendimento, pudessem ser alocados em outras atividades.

Para ampliar os serviços já realizados pela biblioteca, criamos a Biblioteca das Coisas, que consiste no empréstimo de outros materiais e objetos que possam ser úteis à comunidade e tenham relação com o meio acadêmico. O serviço abrange o empréstimo de materiais não bibliográficos como calculadora, carregador de celular, adaptador, notebook, tablets e similares, guarda-chuva, guarda-volumes, fones de ouvido antirruído, entre outros.

Outra mudança da BU Udesc foi a criação da multa solidária, uma alternativa à penalidade recebida pelo atraso na devolução dos livros. Com a doação de alimentos não perecíveis, o usuário anula a suspensão dos seus direitos do empréstimo e, posteriormente, a biblioteca encaminha os alimentos arrecadados às instituições filantrópicas ou Centro de Referência de Assistência Social (CRAS).

\subsection{Serviços voltados à comunicação científica}

Os serviços voltados aos periódicos científicos da Udesc são ofertados pelo Portal de Periódicos Udesc, o qual promove o acesso, a visibilidade, a segurança e o suporte às equi-

${ }^{2}$ O perfil da Biblioteca Universitária no Instagram é @bu.udesc 
pes editoriais da instituição. O Portal contribui para a comunicação científica em acesso aberto e possibilita a curadoria do acervo científico produzido pelos periódicos da instituição.

O serviço de assessoria de publicação científica na BU Udesc teve início em 2020 e conta com atendimento especializado para atender as demandas das equipes editoriais dos periódicos científicos, dos autores que submetem os artigos e dos pareceristas. Orientamos sobre a utilização da plataforma de gerenciamento e publicação dos periódicos, o Open Journal System (OJS); questões de ética editorial e de publicação; indexação das publicações em bases de dados, diretórios, portais de informação e demais mecanismos de divulgação científica e tratamento técnico da informação como metadados e normalização.

O acompanhamento dos periódicos, por meio de levantamentos de dados e elaboração de relatórios, auxilia os editores na gestão dos periódicos de modo a ampliar sua visibilidade e qualidade. Esse serviço da BU Udesc traz benefícios aos editores que agora sabem com quem esclarecer suas dúvidas e levar suas demandas.

Nesse sentido, ofertamos capacitações e disponibilizamos manuais e tutoriais que abordam assuntos como OJS 3, Licenças Creative Commons, indexação de periódicos e revisão de metadados. Todos os conteúdos estão disponíveis no canal do Youtube da BU em uma playlist exclusiva para o Portal.

Outra inovação específica à comunicação cientifica é a oferta de um verificador de similaridade em textos dos artigos aprovados para publicação nos periódicos da Udesc, o que auxilia na prevenção da ocorrência de plágio. Em 2020, foi utilizada a ferramenta iThenticate e realizadas 368 verificações e, em 2021, está em uso o Similarity Check.

\section{CONSIDERAÇÕES FINAIS}

Falar de inovação pode parecer algo simples, mas colocá-la em prática é um desafio. Torna-se pertinente analisar o contexto em que a biblioteca está inserida, pois para inovar geralmente é preciso investimento em recursos humanos e infraestrutura. A cultura organizacional da instituição é fator determinante à inovação, no entanto, sabe-se das limitações que muitas bibliotecas enfrentam para sobreviver. Assim, inovar requer apoio dos setores e das instituições às quais as bibliotecas estão vinculadas.

Considera-se que a BU UDESC aplicou a inovação incremental na medida que trouxe para a Biblioteca a responsabilidade de organizar e estruturar um Clube de Leitura com a colaboração da comunidade, visto que poucas bibliotecas universitárias apresentam essa atividade em seu rol de serviços culturais, com foco no estímulo a leitura.

Outro aspecto relevante é o protagonismo da BU na produção de conteúdo (vídeos, artes) para as mídias sociais (Instagram, YouTube, FanPage), com a criação de um GT específico para a gestão das mídias e aplicação da identidade visual da BU UDESC, pensada por docentes e acadêmicos do curso de Design.

Outras inovações incrementais são o autoatendimento que possibilita mais liberdade e autonomia para o usuário, o serviço de comunicação científica que apoia os editores no processo de comunicação científica, a intensificação nas capacitações que passam a ser regulares e atendem a públicos internos e externos por meio das transmissões ao vivo.

A grande novidade foi a aplicação da cultura presente na identidade visual, refletida nos espaços da biblioteca (físico/virtual), propondo um espaço de colaboração que transcende a biblioteca como um lugar de silêncio, estudo e de custódia do acervo, mas que es- 
timula a criatividade, a construção do conhecimento e que privilegia a cultura e a comunicação.

Os projetos apresentados foram possíveis em virtude da determinação da equipe em tornar real suas ideias e projetos, colocando-os em prática. Aliado a isto está a cultura da instituição em estimular projetos inovadores e investir neles, por meio de recursos financeiros que possibilitaram as transformações de espaços e no apoio à equipe. Como consequência, a biblioteca passa a investir nas ações em que há percepção de valor por parte da comunidade.

Os esforços empreendidos nos projetos apresentados foram assertivos, uma vez que a biblioteca conquistou mais visibilidade e tornou-se referência diante da comunidade, estabeleceu relação de cooperação no ambiente interno e externo e recebeu feedbacks positivos de sua comunidade e pares.

Por fim, acreditamos que inovar é crucial para que a biblioteca continue percebida como um aparelho social necessário nos diferentes setores da sociedade. Então, fica a provocação a partir da seguinte frase de Lankes (2016, p. 24) "muitos bibliotecários veem o acervo e não a comunidade como sua ocupação. Muitas bibliotecas buscam sobreviver em vez de inovar".

\section{REFERÊNCIAS}

ARAÚJO, Wánderson Cássio Oliveira; SILVA, Edna Lucia da; RADOS, Gregório Jean Varvakis. Inovação, competitividade e informação: breves reflexões. Perspectivas em Gestão \& Conhecimento, v. 7, n. 2, 2017. Disponível em:

https://dialnet.unirioja.es/servlet/articulo?codigo=6234309. Acesso em: 01 fev. 2021.

BESSANT, John; TIDD, Joe. Inovação e empreendedorismo. Porto Alegre: Bookman, 2019. Disponível em:

https://app.minhabiblioteca.com.br/\#/books/9788582605189/cfi/1!/4/4@0.00:63.3. Acesso em: 23 abr. 2021.

CORRÊA, Elisa Cristina Delfini. Usuário, não! interagente. proposta de um novo termo para um novo tempo. Encontros Bibli, v. 19, n. 41, p. 23-40, 2014. Disponível em:

https://periodicos.ufsc.br/index.php/eb/article/view/1518-2924.2014v19n41p23/28292.

Acesso em: 04 fev. 2022.

CUNHA, Murilo Bastos da; CAVALCANTI, Cordélia Robalinho de Oliveira. Dicionário de biblioteconomia e arquivologia. Brasília, DF: Briquet de Lemos, 2008.

CUNHA, Murilo Bastos da. A biblioteca universitária na encruzilhada. DataGramaZero, v.11, n.6, dez. 2010. Disponível em: http://repositorio.unb.br/handle/10482/14869. Acesso em: 23 abr. 2021.

LANKES, David. Expect more: melhores bibliotecas para um mundo complexo. São Paulo: FEBAB, 2016.

ORGANIZAÇÃO PARA COOPERAÇÃO E DESENVOLVIMENTO ECONÔMICO. Manual de Oslo: diretrizes para a coleta e interpretação de dados sobre inovação tecnológica. 3. ed. Brasília: 
FINEP, 2006. Disponível em: http://www.finep.gov.br/images/apoio-efinanciamento/manualoslo.pdf. Acesso em: 23 abr. 2021.

ROSSI, Tatiana; VIANNA, William Barbosa. Reestruturação dos serviços prestados em biblioteca universitária. Atoz: Novas Práticas em Informação e Conhecimento, v. 7, n. 2, p. 6-13, 2018. Disponível em: https://revistas.ufpr.br/atoz/article/view/67239/38717. Acesso em: 04 fev. 2022.

UNIVERSIDADE DO ESTADO DE SANTA CATARINA. Conselho de Ensino, Pesquisa e Extensão. Resolução no 036/2019, de 06 de novembro de 2019. Dispõe sobre o Regulamento da Biblioteca Universitária da Fundação Universidade do Estado de Santa Catarina. Florianópolis: Conselho de Ensino, Pesquisa e Extensão, 2019. Disponível em: https://www.udesc.br/arquivos/udesc/id_cpmenu/12336/036_2019_regulamento_bu_1588 9758019028_12336.pdf. Acesso em: 23 abr. 2021.

UNIVERSIDADE DO ESTADO DE SANTA CATARINA. Apresentação. Florianópolis: Udesc, [202?]. Disponível em: https://www.udesc.br/sobre. Acesso em: 23 abr. 2021.

ZANINELLI, Thais Batista; NOGUEIRA, Cibele Andrade; PERES, Ana Luísa Moure. Bibliotecas universitárias: uma perspectiva teórica sobre inovação em serviços informacionais. RDBCI: Revista Digital de Biblioteconomia e Ciência da Informação, v. 17, p. 01-20, jan. 2019. Disponível em: https://periodicos.sbu.unicamp.br/ojs/index.php/rdbci/article/view/8652821. Acesso em: 23 abr. 2021. 